Article

\title{
Supercritical Carbon Dioxide Extraction of Flavonoids from Pomelo (Citrus grandis (L.) Osbeck) Peel and Their Antioxidant Activity
}

\author{
Jin-Zhe He, Ping Shao, Jian-Hua Liu and Qiao-Mei Ru * \\ College of Biological and Environmental Engineering, Zhejiang University of Technology, \\ Hangzhou 310032, China; E-Mails: hejzgd@163.com (J.-Z.H.); pingshao325@zjut.edu.cn (P.S.); \\ jhliu@zjut.edu.cn (J.-H.L.) \\ * Author to whom correspondence should be addressed; E-Mail: ruqiaomei@zjut.edu.cn; \\ Tel.: +86-571-8832-0424; Fax: +86-571-8832-0237.
}

Received: 17 July 2012; in revised form: 11 September 2012 / Accepted: 25 September 2012 / Published: 12 October 2012

\begin{abstract}
Supercritical carbon dioxide $\left(\mathrm{SC}-\mathrm{CO}_{2}\right)$ extraction of flavonoids from pomelo (Citrus grandis (L.) Osbeck) peel and their antioxidant activity were investigated. Box-Behnken design combined with response surface methodology was employed to maximize the extraction yield of flavonoids. Correlation analysis of the mathematical-regression model indicated that a quadratic polynomial model could be used to optimize the $\mathrm{SC}-\mathrm{CO}_{2}$ extraction of flavonoids. The optimal conditions for obtaining the highest extraction yield of flavonoids from pomelo peel were a temperature of $80{ }^{\circ} \mathrm{C}$, a pressure of $39 \mathrm{MPa}$ and a static extraction time of $49 \mathrm{~min}$ in the presence of $85 \%$ ethanol as modifier. Under these conditions, the experimental yield was $2.37 \%$, which matched positively with the value predicted by the model. Furthermore, flavonoids obtained by $\mathrm{SC}-\mathrm{CO}_{2}$ extraction showed a higher scavenging activity on hydroxyl, 1,1-diphenyl-2-picrylhydrazyl (DPPH) and 2,2'-azino-bis(3-ethylbenzthiazoline-6-sulphonic acid) (ABTS) radicals than those obtained by conventional solvent extraction (CSE). Therefore, $\mathrm{SC}-\mathrm{CO}_{2}$ extraction can be considered as a suitable technique for the obtainment of flavonoids from pomelo peel.
\end{abstract}

Keywords: pomelo (Citrus grandis (L.) Osbeck) peel; flavonoids; supercritical carbon dioxide $\left(\mathrm{SC}-\mathrm{CO}_{2}\right)$ extraction; response surface methodology; antioxidant activity 


\section{Introduction}

Supercritical fluid extraction (SFE) has been applied extensively by food and medical industries in recent years, since it is an environment-friendly technology that represents an alternative to conventional extraction methods and offers several advantages over conventional solvent extraction (CSE) methods [1]. Supercritical carbon dioxide $\left(\mathrm{SC}-\mathrm{CO}_{2}\right)$ is the most commonly used solvent in supercritical fluid extraction. $\mathrm{SC}-\mathrm{CO}_{2}$ solvent has highly desirable properties such as non-toxicity, non-flammability, non-explosiveness, low cost, readily availability and ease of removal from the extracted materials [2-5]. Moreover, $\mathrm{CO}_{2}$ has a low critical temperature $\left(T_{\mathrm{c}}=31.1^{\circ} \mathrm{C}\right)$ and technically convenient critical pressure $\left(P_{\mathrm{c}}=73.8 \mathrm{bar}\right)$, which would prevent degradation of thermally labile and reactive components during extraction $[6,7]$.

Pomelo (Citrus grandis (L.) Osbeck), belongs to the family Rutaceae and is a plant native to southeastern Asia. Wang et al. [8] reported that flavonoids have a high distribution of pomelo peel, reaching a concentration of approximately $46.7 \mathrm{mg} / \mathrm{g}$ dry weight. However, pomelo peel is normally thrown away as waste after the enjoyment of this fruit. Although numerous work has been done on flavonoid extraction from citrus peels and their antioxidant effect [9-12], no researches on flavonoids extraction from pomelo peel by $\mathrm{SC}-\mathrm{CO}_{2}$ extraction technique and their antioxidant property are available until now.

In this study, $\mathrm{SC}-\mathrm{CO}_{2}$ extraction technique was used to extract flavonoids from the pomelo peel. The efficiency of $\mathrm{SC}-\mathrm{CO}_{2}$ extraction technique is affected by numerous factors, particularly temperature, pressure, supercritical $\mathrm{CO}_{2}$ flux, presence of a modifier and extraction time, which can affect the supercritical fluid selectivity, yield and extraction rate [13]. In order to maximize extraction yield, response surface methodology was employed to optimize the key parameters of $\mathrm{SC}-\mathrm{CO}_{2}$ extraction. Moreover, the efficiency of SC- $\mathrm{CO}_{2}$ extraction of flavonoids was compared with that of CSE. Furthermore, the antioxidant activity of purified flavonoids of pomelo peel was determined by means of scavenging abilities of hydroxyl, 2,2-diphenyl-1-picrylhydrazyl (DPPH) and 2,2'-azino-bis(3ethylbenzthiazoline-6-sulphonic acid) (ABTS) radicals.

\section{Results and Discussion}

\subsection{Optimization of $\mathrm{SC}-\mathrm{CO}_{2}$ Extraction Parameters by Response Surface Methodology}

\subsubsection{Model Fitting}

The experimental design and corresponding response values are listed in Table 1. The mathematical model representing the extraction yield of flavonoids as a function of the independent variables within the region under investigation was expressed by the following equation:

$$
Y=2.14+0.098 x_{1}+0.11 x_{2}+0.10 x_{3}+0.064 x_{1} x_{2}+0.16 x_{1} x_{3}-0.005 x_{2} x_{3}+0.032 x_{1}^{2}-0.16 x_{2}^{2}-0.29 x_{3}^{2}
$$

Analysis of variance (ANOVA) for the response surface quadratic model was used to explore the linearity and quadratic effect of the treatment variables, their interactions and coefficients on the response of the extraction yield (Table 2). The significance of each coefficient was determined by $p$-values. As shown in Table 2, $p$-values of the monomial coefficients $x_{1}, x_{2}$ and $x_{3}$ were all less than 
0.01, indicating that temperature, pressure and static extraction time as the linear terms were highly significant. Moreover, $p$-values for the quadratic coefficients $x_{1}{ }^{2}$ and $x_{3}{ }^{2}$ were significant $(p<0.01$ and $p<0.001$, respectively), which suggested that the quadratic terms of temperature and static extraction time had a significant effect on extraction yield. Furthermore, the $p$-value of the interaction coefficient $x_{1} x_{3}$ was lower than 0.01 , indicating that the pairwise interaction model of temperature and static extraction time was highly significant, and there were significant interactions with extraction yield. However, the other two interaction coefficients $x_{1} x_{2}$ and $x_{2} x_{3}$ were insignificant $(p>0.05)$, indicating that interactions between temperature and pressure or interactions between pressure and static extraction time did not have effect on the extraction yield.

Table 1. Box-Behnken design and response for the extraction yield of pomelo peel.

\begin{tabular}{cccccc}
\hline & \multicolumn{3}{c}{ Coded level } & \multicolumn{2}{c}{ Response Extraction yield (\%) ${ }^{\mathbf{a}}$} \\
\cline { 2 - 5 } Run & $\begin{array}{c}\boldsymbol{x}_{\mathbf{1}} \\
\text { Temperature }\left({ }^{\circ} \mathbf{C}\right)\end{array}$ & $\begin{array}{c}\boldsymbol{x}_{\mathbf{2}} \\
\text { Pressure (MPa) }\end{array}$ & $\begin{array}{c}\boldsymbol{x}_{\mathbf{3}} \\
\text { Time (min) }\end{array}$ & Predicted & Experimental $^{\mathbf{b}}$ \\
\hline 1 & $-1(60)$ & $-1(28)$ & $0(40)$ & 1.86 & $1.80 \pm 0.081$ \\
2 & $1(80)$ & $-1(28)$ & $0(40)$ & 1.93 & $1.97 \pm 0.093$ \\
3 & $-1(60)$ & $1(42)$ & $0(40)$ & 1.96 & $1.92 \pm 0.027$ \\
4 & $1(80)$ & $1(42)$ & $0(40)$ & 2.29 & $2.35 \pm 0.106$ \\
5 & $-1(60)$ & $0(35)$ & $-1(20)$ & 1.84 & $1.92 \pm 0.065$ \\
6 & $1(80)$ & $0(35)$ & $-1(20)$ & 1.71 & $1.69 \pm 0.046$ \\
7 & $-1(60)$ & $0(35)$ & $1(60)$ & 1.72 & $1.74 \pm 0.059$ \\
8 & $1(80)$ & $0(35)$ & $1(60)$ & 2.24 & $2.16 \pm 0.110$ \\
9 & $0(70)$ & $-1(28)$ & $-1(20)$ & 1.48 & $1.46 \pm 0.052$ \\
10 & $0(70)$ & $1(42)$ & $-1(20)$ & 1.69 & $1.65 \pm 0.074$ \\
11 & $0(70)$ & $-1(28)$ & $1(60)$ & 1.67 & $1.71 \pm 0.042$ \\
12 & $0(70)$ & $1(42)$ & $1(60)$ & 1.91 & $1.93 \pm 0.063$ \\
13 & $0(70)$ & $0(35)$ & $0(40)$ & 2.14 & $2.19 \pm 0.114$ \\
14 & $0(70)$ & $0(35)$ & $0(40)$ & 2.14 & $2.13 \pm 0.092$ \\
15 & $0(70)$ & $0(35)$ & $0(40)$ & 2.14 & $2.07 \pm 0.088$ \\
16 & $0(70)$ & $0(35)$ & $0(40)$ & 2.14 & $2.11 \pm 0.056$ \\
17 & $0(70)$ & $0(35)$ & $0(40)$ & 2.14 & $2.18 \pm 0.079$ \\
\hline
\end{tabular}

${ }^{a}$ Extraction yield is the percentage of the extracted flavonoids with respect to the dry weight of pomelo peel;

${ }^{\mathrm{b}}$ Data are means \pm standard deviation of triplicate experiments.

Generally, exploration and optimization of a fitted response surface may produce poor or misleading results unless the model exhibits a good fit, which makes checking the adequacy of the model essential [14]. The model would be more significant if the absolute $F$-value rises and the $p$-value lowers. The $F$-value and $p$-value of model were 17.31 and 0.0005 , respectively, attesting that the model fitness was significant. Meanwhile, $F$-value for the lack of fit was insignificant ( $p=0.1048)$ thereby implying the validity of the model. The fit of the polynomial model can be checked by the coefficient $\left(R^{2}\right)$ of determination [15]. The closer the value of adjusted $R^{2}$ is to 1 , the better fit the model has and the better it predicts the response [16]. The value of adjusted $R^{2}(0.9570)$ for Equation 1 suggested that the fitness between the predicted and actual values are good, where the total variation of $95.7 \%$ was attributed to the independent variables and only about $4.3 \%$ of the total variation cannot be explained by the model. 
Finally, the normal probability plot and the residual plot verified the assumptions of randomness, normality and constant variances of the residuals. Therefore, the quadratic model was found to be adequate in describing the response surface for the flavonoid extraction from pomelo peel.

Table 2. Analysis of variance (ANOVA) and estimated regression coefficients for response surface quadratic model.

\begin{tabular}{cccccc}
\hline Source & Sum of squares & DF $^{\text {a }}$ & Mean square & $\boldsymbol{F}$-Value & Prob $>\boldsymbol{F}$ \\
\hline Linear & & & & & \\
$x_{1}$ & 0.077 & 1 & 0.077 & 13.73 & 0.0076 \\
$x_{2}$ & 0.10 & 1 & 0.10 & 18.16 & 0.0037 \\
$x_{3}$ & 0.085 & 1 & 0.085 & 15.05 & 0.0061 \\
Quadratic & & & & \\
$x_{1}{ }^{2}$ & $4.265 \times 10^{-3}$ & 1 & $4.265 \times 10^{-3}$ & 0.76 & 0.1308 \\
$x_{2}{ }^{2}$ & 0.11 & 1 & 0.11 & 19.16 & 0.0032 \\
$x_{3}$ & 0.36 & 1 & 0.36 & 63.63 & $<0.0001$ \\
Interaction & & & & & \\
$x_{1} x_{2}$ & 0.017 & 1 & 0.017 & 2.93 & 0.1308 \\
$x_{1} x_{3}$ & 0.11 & 1 & 0.11 & 19.19 & 0.0032 \\
$x_{2} x_{3}$ & $1.000 \times 10^{-3}$ & 1 & $1.000 \times 10^{-4}$ & 0.018 & 0.8978 \\
Model & 0.88 & 9 & 0.098 & 17.31 & 0.0005 \\
Residual & 0.039 & 7 & $5.639 \times 10^{-3}$ & & \\
Lack of fit & 0.030 & 3 & $9.902 \times 10^{-3}$ & 4.06 & 0.1048 \\
Pure error & $9.767 \times 10^{-3}$ & 4 & $2.442 \times 10^{-3}$ & & \\
Cor total & 0.92 & 16 & & & \\
$R^{2}=0.9776$ & & & & & \\
Adj. $R^{2}=0.9570$ & & & & & \\
\hline
\end{tabular}

${ }^{\mathrm{a}}$ Degree of freedom.

\subsubsection{Response Surface Analysis}

The best way of expressing the effect of any independent variable on the flavonoid extraction yield is to generate surface response plots of the model, which were done by varying two variables within the experimental range under investigation and keeping the third variable at its " 0 " level [17]. The relationship between independent and dependent variables is illustrated in contour and 3-D response surface plots generated by the model for extraction yield (Figure 1). The response surface plots revealed that there was a region where neither an increasing nor a decreasing trend in the extraction capacity was observed, suggesting that there was an optimal condition for the extraction variables in order to maximize the extraction yield of flavonoids from pomelo peel.

The contour and 3-D response surface plots in Figure 1a,b shows the effects of pressure and temperature on the extraction yield of flavonoids at fixed static extraction time (level $=0$, static extraction time $=40 \mathrm{~min}$ ). By increasing pressure, the extraction yield was increased until reaching a highest value when the pressure was at 38-40 MPa. This could be due to the increase of solvent power and density of the $\mathrm{SC}-\mathrm{CO}_{2}$ with the pressure [14]. However, further a increasing of the pressure resulted in little change in the extraction yield of flavonoids. The probable reason was that the highly 
compressed $\mathrm{CO}_{2}$ facilitates solute-solvent repulsion. Thus, high pressure is not always recommended, as it can potentially induce complex extraction and complicate the analysis [14]. When the temperature was increased from 60 to $80{ }^{\circ} \mathrm{C}$, the extraction yield was increased from $1.94 \%$ to $2.35 \%$. It was evident that temperature had a positive effect on extraction yield of flavonoids. Probably the increase of temperature could accelerate the mass transfer ratio, thus increasing the extraction yield [18]. This result suggested that operating at a higher temperature and a suitable pressure would favor the extraction of flavonoids from pomelo peel.

Figure 1. Contour (a, $\mathbf{c}$ and $\mathbf{e})$ and 3-D response surface plots (b, d, and $\mathbf{f})$ showing the effects of temperature, pressure and static extraction time on the extraction yield of flavonoids and their interactions. (a) and (b) at varying temperature and pressure, (c) and (d) at varying temperature and static extraction time, (e) and (f) at varying pressure and static extraction time.

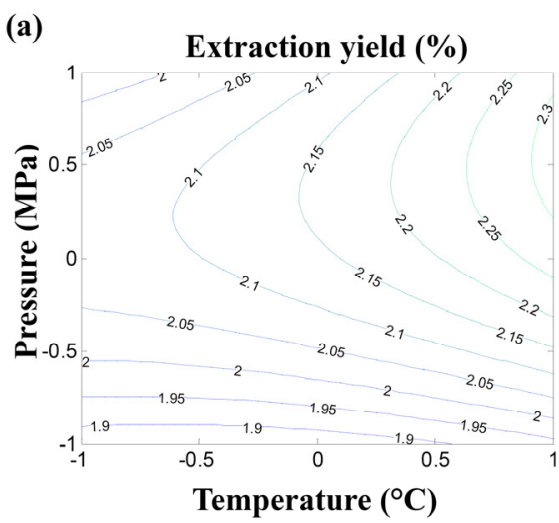

(c)

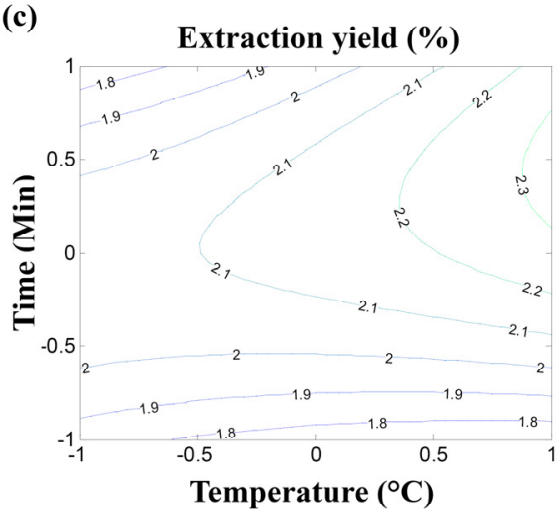

(e)

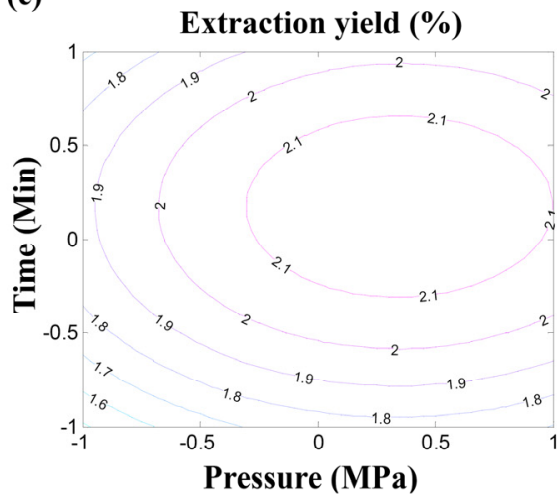

(b)

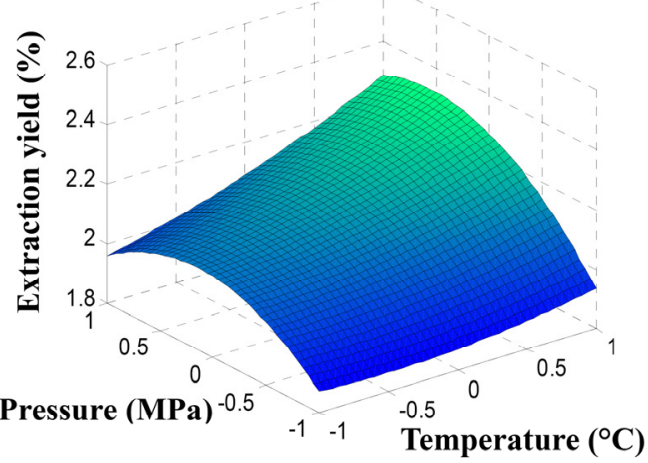

(d)

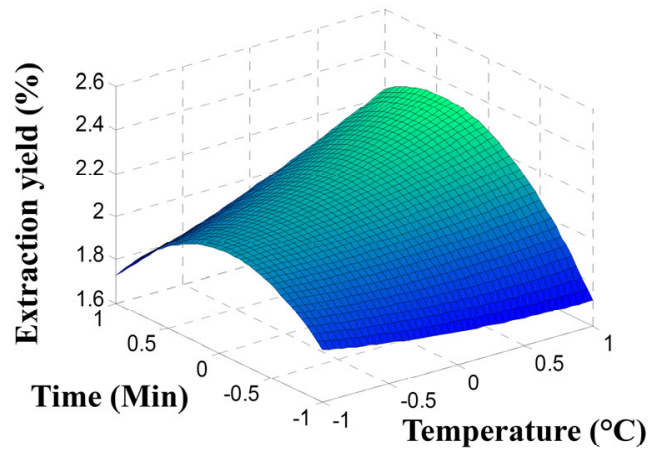

(f)

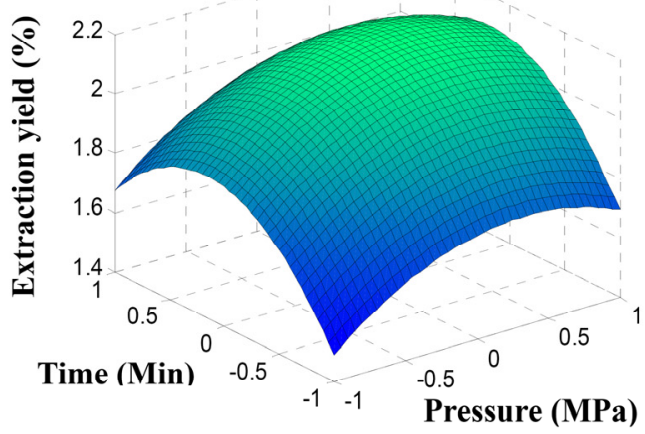


The contour and 3-D response surface plots of temperature and static extraction time at fixed pressure (level $=0$, pressure $=35 \mathrm{MPa}$ ) are shown in Figure 1c,d. Similarly, increasing the temperature would increase the extraction yield of flavonoids and increasing the static extraction time, the extraction yield was also increased until an optimum value was reached at 45-52 min of static extraction time. However, further extending the reaction time resulted in little change in the extraction yield of flavonoids. These results were in accordance with previous studied [19,20]. By increasing the temperature from 60 to $80{ }^{\circ} \mathrm{C}$, the extraction yield was increased from $1.97 \%$ to $2.34 \%$. This indicated that operating at a higher temperature for a suitable static extraction time would promote the extraction of flavonoids from pomelo peel.

As shown in Figure 1e,f, extraction yield of flavonoids was affected by varying the pressure and static extraction time when the temperature was fixed at $70{ }^{\circ} \mathrm{C}($ level $=0)$. It could be seen from the contour and 3-D response surface plots that the extraction yield was increased with increasing pressure until the pressure reached $39 \mathrm{MPa}$. In addition, the extraction yield of flavonoids was also increased until an optimum value was reached at $49 \mathrm{~min}$ of static extraction time. This indicated that operating at a suitable pressure and static extraction time would contribute to the extraction of flavonoids from pomelo peel. There was significant interaction between pressure and static extraction time. The static extraction time required to reach maximum yield was higher than that needed at higher-pressure levels.

\subsubsection{Optimum Conditions and Model Verification}

The best fit extraction parameters can be validated by a stationary point of the optimized regression model. The stationary point is the combination of design variables where the surface is at either a maximum or a minimum in all directions, which can be found by using matrix algebra [21]. The solutions of stationary points of independent variables were calculated by using Design Expert software, and the results were: $x_{1}=0.981, x_{2}=0.540$ and $x_{3}=0.443$.

According to Equation 2, the stationary points in terms of the natural variables were found:

$$
0.981=\frac{X_{1}-70}{10} \quad 0.540=\frac{X_{2}-35}{7} \quad 0.443=\frac{X_{3}-40}{20}
$$

Thus, the calculated best fit extraction parameters were temperature of $79.81{ }^{\circ} \mathrm{C}$, pressure of $38.78 \mathrm{MPa}$ and static extraction time of $48.86 \mathrm{~min}$, which were consistent with the optimal conditions of $\mathrm{SC}-\mathrm{CO}_{2}$ extraction process to obtain the highest extraction yield selected on the basis of response surface (Figure 1).

The optimum extraction conditions $\left(X_{1}=79.81{ }^{\circ} \mathrm{C}, X_{2}=38.78 \mathrm{MPa}\right.$ and $\left.X_{3}=48.86 \mathrm{~min}\right)$ for the flavonoid extraction yield were estimated, and the predicted extraction yield of flavonoids from pomelo peel under the above conditions was $2.38 \%$. To validate the predicted values, three additional validation runs were conducted. To ensure the predicted result was not biased toward the practical value, experiment rechecking was performed by using these modified optimal conditions: temperature of $80{ }^{\circ} \mathrm{C}$, pressure of $39 \mathrm{MPa}$, and static extraction time of $49 \mathrm{~min}$. The mean extraction yield for the flavonoids was $2.37 \% \pm 0.083 \%(n=3)$, corresponding well to the predicted value of the model equation, which confirmed that the response model was adequate for the optimization (Table 3 ). 
Table 3. Predicted and experimental values at optimum conditions.

\begin{tabular}{ccccc}
\hline Extraction conditions & $\begin{array}{c}\text { Temperature } \\
\left({ }^{\circ} \mathbf{C}\right)\end{array}$ & $\begin{array}{c}\text { Pressure } \\
(\mathbf{M P a})\end{array}$ & $\begin{array}{c}\text { Extraction time } \\
(\mathbf{m i n})\end{array}$ & Extraction yield (\%) $^{\text {a }}$ \\
\hline Optimum conditions & 79.81 & 38.78 & 48.86 & 2.38 (predicted) \\
Modified conditions & 80 & 39 & 49 & $2.37 \pm 0.083^{\mathrm{b}}$ (experimental) \\
\hline \multicolumn{4}{c}{ Extraction yield is the percentage of the extracted flavonoids with respect to the dry weight of pomelo peel; } \\
${ }^{\mathrm{b}}$ Data are mean \pm standard deviation of triplicate experiments.
\end{tabular}

\subsection{Comparison of $\mathrm{SC}-\mathrm{CO}_{2}$ Extraction and $\mathrm{CSE}$}

Different methods for natural matter extraction have different extraction yield and efficiency. A comparison of extraction yield of flavonoids between $\mathrm{SC}-\mathrm{CO}_{2}$ extraction and CSE under optimal extracting conditions is shown in Table 4. Table 4 shows that $\mathrm{SC}-\mathrm{CO}_{2}$ extraction could produce an extraction yield of $2.37 \% \pm 0.083 \%$, which was more efficient than CSE $(1.51 \% \pm 0.061 \%)$. In addition, the extraction time of $\mathrm{SC}-\mathrm{CO}_{2}$ extraction was only $49 \mathrm{~min}$, far lower than CSE (120 min). The results showed that $\mathrm{SC}-\mathrm{CO}_{2}$ extraction was more efficient than $\mathrm{CSE}$. Therefore, $\mathrm{SC}-\mathrm{CO}_{2}$ extraction technique can be recommended as a suitable extraction method to isolate flavonoids from pomelo peel.

Table 4. Comparison of SC- $\mathrm{CO}_{2}$ extraction and $\mathrm{CSE}$ of extraction yield of flavonoids from pomelo peel.

\begin{tabular}{cccc}
\hline Extraction method & Temperature $\left({ }^{\circ} \mathbf{C}\right)$ & Extraction time (min) & Extraction yield $(\%){ }^{\text {a }}$ \\
\hline $\mathrm{SC}-\mathrm{CO}_{2}$ extraction & 80 & 49 & $2.37 \pm 0.083^{*}$ \\
$\mathrm{CSE}$ & 85 & 120 & $1.51 \pm 0.061$ \\
\hline
\end{tabular}

${ }^{a}$ Flavonoid yield is the percentage of the extracted flavonoids with respect to the dry weight of pomelo peel; data are means \pm standard deviation of triplicate experiments. $*$ Significant difference was determined at $p<0.05$.

\subsection{Antioxidant Property}

The model of scavenging the stable DPPH radicals has been widely accepted as a tool to evaluate the free radical-scavenging activities of materials [22]. Figure 2a describes the scavenging ability of purified flavonoids from pomelo peel on DPPH radicals. At all concentrations tested, flavonoids exhibited a dose-dependent DPPH radical-scavenging activity. The scavenging abilities of flavonoids extracted by SC- $\mathrm{CO}_{2}$ extraction and CSE on DPPH radicals were from $35.52 \%$ to $96.31 \%$ and from $21.43 \%$ to $73.25 \%$, respectively, with concentration increasing from 12.5 to $200 \mu \mathrm{g} / \mathrm{mL}$. The $\mathrm{EC}_{50}$ values of scavenging ability on DPPH radicals for flavonoids extracted by $\mathrm{SC}-\mathrm{CO}_{2}$ extraction and $\mathrm{CSE}$ were $26 \mu \mathrm{g} / \mathrm{mL}$ and $60 \mu \mathrm{g} / \mathrm{mL}$, respectively, indicating that flavonoids extracted by $\mathrm{SC}^{-\mathrm{CO}_{2}}$ extraction had a higher scavenging activity on DPPH radicals than that by CSE. The scavenging abilities of the flavonoids extracted by $\mathrm{SC}-\mathrm{CO}_{2}$ extraction and $\mathrm{CSE}$ on DPPH radicals were all relatively lower than that of vitamin $\mathrm{C}(\mathrm{Vc})\left(\mathrm{EC}_{50}=22 \mu \mathrm{g} / \mathrm{mL}\right)$. However, at $200 \mu \mathrm{g} / \mathrm{mL}$, the DPPH radical-scavenging activity of flavonoids extracted by $\mathrm{SC}-\mathrm{CO}_{2}$ extraction was equivalent to the scavenging activity of $\mathrm{Vc}$ used in this study. 
Figure 2. Scavenging abilities of the flavonoids extracted from pomelo peel on, DPPH (a), ABTS (b) and hydroxyl (c) radicals. Data are means \pm standard deviation of triplicate experiments.
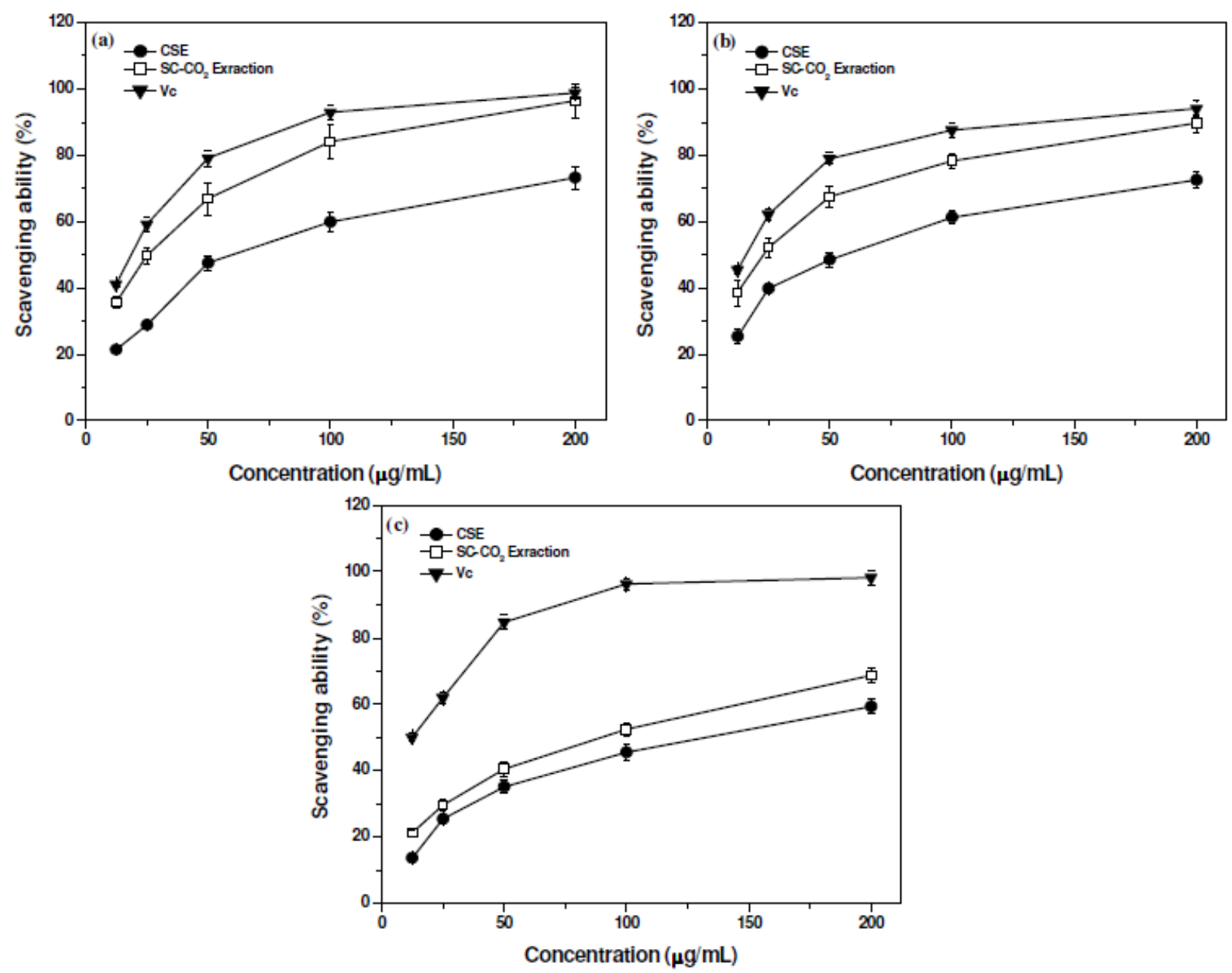

ABTS assay is often used in evaluating total antioxidant power of single compounds and complex mixtures of various plants [23]. Figure $2 b$ reveals the scavenging ability of flavonoids from pomelo peel on ABTS radicals. In this assay, the concentration-dependent profile of scavenging activity on ABTS radicals was obvious for the tested flavonoids. The scavenging abilities of flavonoids extracted by SC- $\mathrm{CO}_{2}$ extraction and CSE on ABTS radicals were from $38.63 \%$ to $89.74 \%$ and from $25.35 \%$ to $75.23 \%$, respectively, with concentration range of $12.5-200 \mu \mathrm{g} / \mathrm{mL}$. Flavonoids extracted by $\mathrm{SC}-\mathrm{CO}_{2}$ extraction revealed a better antioxidant activity because the $\mathrm{EC}_{50}$ values of scavenging ability on ABTS radicals for flavonoids extracted by $\mathrm{SC}-\mathrm{CO}_{2}$ extraction and $\mathrm{CSE}$ were $23 \mu \mathrm{g} / \mathrm{mL}$ and $56 \mu \mathrm{g} / \mathrm{mL}$, respectively. Although flavonoids of pomelo peel showed a lower scavenging activity on ABTS radicals than $\mathrm{Vc}\left(\mathrm{EC}_{50}=17 \mu \mathrm{g} / \mathrm{mL}\right)$, the ABTS radical-scavenging activity of flavonoids extracted by $\mathrm{SC}-\mathrm{CO}_{2}$ extraction was to be equal to that of $\mathrm{Vc}$ at $200 \mu \mathrm{g} / \mathrm{mL}$.

Removing hydroxyl radicals is important for the protection of living systems because they are considered to be mainly responsible for the oxidative injury of biomolecules [24]. Scavenging ability of the flavonoids isolated from pomelo peel on hydroxyl radicals is depicted in Figure 2c. In this work, the scavenging abilities of flavonoids extracted by $\mathrm{SC}-\mathrm{CO}_{2}$ extraction and CSE on hydroxyl radicals were concentration-dependent, which were from $21.24 \%$ to $68.71 \%$ and from $13.72 \%$ to $59.33 \%$, 
respectively, with concentration varying from 12.5 to $200 \mu \mathrm{g} / \mathrm{mL}$. The $\mathrm{EC}_{50}$ values of scavenging ability on hydroxyl radicals for flavonoids extracted by $\mathrm{SC}-\mathrm{CO}_{2}$ extraction and CSE were $80 \mu \mathrm{g} / \mathrm{mL}$ and $135 \mu \mathrm{g} / \mathrm{mL}$, respectively, proving that flavonoids extracted by $\mathrm{SC}-\mathrm{CO}_{2}$ extraction were better scavengers for hydroxyl radicals than those by CSE, although the scavenging ability of the flavonoids extracted by $\mathrm{SC}-\mathrm{CO}_{2}$ extraction on hydroxyl radicals was relatively lower than that of $\mathrm{Vc}$ $\left(\mathrm{EC}_{50}=12.5 \mu \mathrm{g} / \mathrm{mL}\right)$.

The antioxidant capacity of flavonoids from pomelo peel was assessed with the scavenging abilities of DPPH, ABTS and hydroxyl radicals. Our results indicated that flavonoids prepared by $\mathrm{SC}-\mathrm{CO}_{2}$ extraction was found to have a significantly higher antioxidant activity than that obtained by CSE. The antioxidants are believed to donate hydrogen from the phenolic hydroxyl groups and break the free radical chain of oxidation forming a stable end product, which does not initiate or propagate further oxidation [25]. The high antioxidant activity of flavonoids can be attributed to hydroxy groups in the A- and B-rings, and the larger the number of hydroxy groups, the higher is the capacity to scavenge free radicals [26]. For flavonoids extracted by $\mathrm{SC}-\mathrm{CO}_{2}$ extraction, their high antioxidant activity could be attributed to the high presence of phenolic hydroxyl group flavonoids.

\section{Experimental Section}

\subsection{Plant Material and Chemicals}

Pomelo was purchased from Yuhuan County, Zhejiang Province, China. The peel was washed and dried in an oven at $60{ }^{\circ} \mathrm{C}$ for $48 \mathrm{~h}$ to a moisture content of $8.0 \%$, then ground to homogeneous powder ( $0.5 \mathrm{~mm}$ diameter) by an electrical food grinder.

Carbon dioxide (99.99\% purity) supplied in a cylinder with a dip tube was purchased from Hangzhou Jinggong Specialty Gases Co., Ltd. (Hangzhou, China). ABTS, DPPH and Vitamin C (Vc) were purchased from Sigma Chemical Co. (St. Louis, MO, USA). All other chemicals were analytical grade and purchased from Shanghai Boer Chemical Reagent Co., Ltd. (Shanghai, China).

\subsection{Supercritical $\mathrm{CO}_{2}$ Extraction}

A supercritical fluid extractor Spe-ed SFE-2 (Applied Separation, USA) was used, which operates with two pumps, a master pump fitted with a cooling jacket on the pump head and a second pump (Knauer pump, model K-501, Berlin, Germany) for the addition of organic modifier. For extraction using SFE, $4 \mathrm{~g}$ dried pomelo peel powder was placed in a $30 \mathrm{~mL}$ extraction vessel. $85 \%$ aqueous ethanol was chosen as a modifier in this study. The static extraction was started when the desired pressure and specified temperature were reached. The operating pressure was provided by an air compressor. The extracted analyte was collected in glass vial with a rubber plug at the top. The $\mathrm{CO}_{2}$ flow rate was kept at approximately $1.0 \mathrm{~mL} / \mathrm{min}$ by adjusting the outlet valve manually. The extraction was then performed under various experimental conditions in accordance with the experimental design. In order to assure the accuracy of the experimental data, the experiment was performed in triplicate. 


\subsection{Experimental Design}

The three independent variables were $X_{1}, X_{2}$ and $X_{3}$ representing temperature, pressure and static extraction time, respectively, while the dependent variable was the extraction yield. For statistical calculation, the variables were coded according to:

$$
x_{i}=\frac{X_{i}-X_{0}}{\delta X}
$$

where $x_{i}$ is the coded value of an independent variable, $X_{i}$ is the real value of the independent variable, $X_{0}$ is the real value of an independent variable at the center point, and $\delta X$ is the step change value.

The experimental runs were designed in accordance with a Box-Behnken design with three factors and three levels. According to the single factor experiments, the settings for independent variables were as follows for the low and high values: temperatures of 60 and $80{ }^{\circ} \mathrm{C}$; pressures of 28 and $42 \mathrm{MPa}$; and static extraction time of 20 and $60 \mathrm{~min}$. Each variable was coded at three levels: $-1,0$ and +1 . The symbols and levels are shown in Table 5. From the Box-Behnken design, seventeen experimental runs were required, and five replicates at the center $(0,0,0)$ of the design were performed to allow the estimation of the pure error sum of squares.

Table 5. Independent variables and their levels in the Box-Behnken design.

\begin{tabular}{ccccc}
\hline \multirow{2}{*}{ Independent variable } & \multirow{2}{*}{ Coded symbol } & \multicolumn{3}{c}{ Variable level } \\
\cline { 3 - 5 } & & $-\mathbf{1}$ & $\mathbf{0}$ & $\mathbf{1}$ \\
\hline Temperature $\left({ }^{\circ} \mathrm{C}\right)$ & $x_{1}$ & 60 & 70 & 80 \\
Pressure $(\mathrm{MPa})$ & $x_{2}$ & 28 & 35 & 42 \\
Time $(\mathrm{min})$ & $x_{3}$ & 20 & 40 & 60 \\
\hline
\end{tabular}

Experimental data were fitted to a quadratic polynomial model using regression coefficients. The generalized quadratic polynomial model used in the response surface analysis was described in Equation 4:

$$
Y_{i}=\beta_{0}+\sum_{i=1}^{k} \beta_{i} x_{i}+\sum_{i=1}^{k} \beta_{i i} x_{i}^{2}+\sum \sum_{i \leq j} \beta_{i j} x_{i j}+\varepsilon_{i}
$$

where $Y_{i}$ is the predicted response, $\beta_{0}, \beta_{i}, \beta_{i i}$ and $\beta_{i j}$ are the regression coefficients for intercept, linearity, square and interaction, respectively, while $x_{i}$ and $x_{j}$ are the independent code variables. The cross terms represent two-parameter interactions, and the quadratic terms represent second-order non-linearity, while $\varepsilon$ is the statistical error that represents other sources of variability, such as measurement error.

\subsection{Conventional Solvent Exraction (CSE)}

Ten grams dried pomelo peel powder was placed in a reflux apparatus. Extraction was performed with $150 \mathrm{~mL}$ of $85 \%$ aqueous ethanol for $120 \mathrm{~min}$ at $85{ }^{\circ} \mathrm{C}$. The crude extract was filtered. The solution was concentrated under reduced pressure. The procedure was performed in triplicate. 


\subsection{Determination of Flavonoid Content}

The content of flavonoids was determined using a method described by Yi et al. [12] with several modifications. Briefly, $1 \mathrm{~mL}$ diluted sample was mixed with $1 \mathrm{~mL}$ of $5 \%(w / w) \mathrm{NaNO}_{2}$. After 6 min, $1 \mathrm{~mL}$ of $10 \%(w / w) \mathrm{AlCl}_{3}$ was added and allowed to stand for $6 \mathrm{~min}$, then $5 \mathrm{~mL}$ of $4 \%(w / w) \mathrm{NaOH}$ was added to the mixture. Absorbance was taken at $510 \mathrm{~nm}$ after $15 \mathrm{~min}$. The content of flavonoids was expressed as rutin equivalents through the calibration curve of rutin. The calibration curve $(y=0.5923 x-0.0021$, where $y$ is absorbance of sample, $x$ is sample concentration) ranged $10-1000 \mu \mathrm{g} / \mathrm{mL}$ $\left(R^{2}=0.9996\right)$.

\subsection{Purification of Flavonoids by Macroporous Resin Adsorption}

The crude flavonoids-enriched extract obtained under the optimized condition was purified using a column $\left(25 \times 1.5 \mathrm{~cm}^{2}\right)$ packed with $\mathrm{AB}-8$ macroporous adsorption resin according to the reference [17]. The conditions for purifying the flavonoids by AB- 8 resin were: injecting concentration $3.75 \mathrm{mg} / \mathrm{mL}$, $\mathrm{pH}=5$, injecting velocity $2.0 \mathrm{~mL} / \mathrm{min}, 40 \%(\mathrm{v} / \mathrm{v})$ ethanol as desorption solvent, desorption velocity of flow $1.5 \mathrm{~mL} / \mathrm{min}$. The purified extract of flavonoids was collected and evaporated at $50{ }^{\circ} \mathrm{C}$, and was then freeze-dried for determination of antioxidant property.

\subsection{Assay of Antioxidant Property}

In order to evaluate antioxidant activity of flavonoids from pomelo peel, $\mathrm{AB}-8$ macroporous adsorption resin was employed to purify the flavonoids obtained by $\mathrm{SC}-\mathrm{CO}_{2}$ extraction and CSE. The antioxidant activity was investigated using biochemical methods of DPPH, ABTS and hydroxyl radical scavenging assay. Tests were carried out in triplicate.

The DPPH radical-scavenging activity was measured according to the method of Braca et al. [27]. Flavonoid sample with different concentrations $(12.5-200 \mu \mathrm{g} / \mathrm{mL}, 1.0 \mathrm{~mL})$ was mixed with methanol solution $(3.0 \mathrm{~mL})$ containing DPPH radicals $(0.2 \mathrm{mM})$. The mixture was shaken vigorously and incubated for $30 \mathrm{~min}$ in darkness at room temperature, and then absorbance at $517 \mathrm{~nm}$ was measured.

The scavenging activity of the flavonoids against ABTS radicals $\left(\mathrm{ABTS}^{+}\right)$was measured using the method of Fellegrini et al. [28] with some modifications. $\mathrm{ABTS}^{+}$were produced by reacting ABTS solution $(7 \mathrm{mM}, 25 \mathrm{~mL})$ with potassium persulphate $(1.4 \mathrm{mM}, 0.44 \mathrm{~mL})$, and the mixture was kept in the dark at room temperature for $12 \sim 16 \mathrm{~h}$. In the moment of use, the $\mathrm{ABTS}^{+}$solution was diluted with ethanol $(475 \mathrm{~mL})$ to an absorbance of $0.70 \pm 0.02$ at $734 \mathrm{~nm}$. Flavonoid sample with different concentrations $(12.5-200 \mu \mathrm{g} / \mathrm{mL}, 1.0 \mathrm{~mL})$ was added to $\mathrm{ABTS}^{+}$solution $(3.0 \mathrm{~mL})$ and mixed vigorously. After reaction at room temperature for $6 \mathrm{~min}$, the absorbance at $734 \mathrm{~nm}$ was measured.

Hydroxyl radical-scavenging activity was determined based on the method described by Smirnoff and Cumbes [29] with some modifications. The reaction mixture contained flavonoid sample with different concentrations $(12.5-200 \mu \mathrm{g} / \mathrm{mL}, 1 \mathrm{~mL})$ was incubated with a solution containing orthophenanthroline $(5 \mathrm{mM}, 1 \mathrm{~mL})$, phosphate buffer $(7.5 \mathrm{mM}, \mathrm{pH} 7.4,0.8 \mathrm{~mL})$ and $\mathrm{FeSO}_{4}(7.5 \mathrm{mM}$, $0.5 \mathrm{~mL})$. Finally, $\mathrm{H}_{2} \mathrm{O}_{2}(8.8 \mathrm{mM}, 0.5 \mathrm{~mL})$ was added, and the reaction mixture was then incubated at $37^{\circ} \mathrm{C}$ for $1 \mathrm{~h}$. The absorbance of the resulting solution was measured spectrophotometrically at $532 \mathrm{~nm}$. 
The radical scavenging ability was calculated using the following formula: scavenging ability $(\%)=\left(1-A_{\text {sample }} / A_{\text {control }}\right) \times 100$, where $A_{\text {control }}$ is the absorbance of control without the flavonoid sample, and $A_{\text {sample }}$ is the absorbance in the presence of the flavonoid sample. The $\mathrm{EC}_{50}$ value $(\mu \mathrm{g} / \mathrm{mL})$ is the effective concentration at which the hydroxyl, DPPH or ABTS radicals are scavenged by $50 \%$. Vc was used as reference compound.

\subsection{Statistical Analysis}

Each experiment was performed three times and the results were expressed as mean \pm standard deviation of three replications. The software Design Expert (Trial Version 7.1.3.; Stat-Ease Inc.: Minneapolis, MN, USA) was used for experimental design, data analysis, quadratic model buildings, and graph (three-dimensional response surface and contour) plotting. $p$ value $<0.05$ was regarded as significant and $p$ value $<0.001$ as highly significant.

\section{Conclusions}

In this study, the $\mathrm{SC}-\mathrm{CO}_{2}$ extraction of flavonoids from pomelo peel was investigated with three-variable (temperature, pressure and static extraction time), three-level experiment. Box-Behnken design and response surface methodology were applied to maximize the extraction yield of flavonoids. The optimal extraction conditions for the flavonoids were determined as follows: temperature of $80{ }^{\circ} \mathrm{C}$, a pressure of $39 \mathrm{MPa}$, a static extraction time of $49 \mathrm{~min}$ and with $85 \%$ aqueous ethanol as modifier. Under these conditions, the experimental yield of flavonoids was $2.37 \% \pm 0.083 \%$, which was closed with the predicted yield value. Compared to $\mathrm{CSE}, \mathrm{SC}-\mathrm{CO}_{2}$ extraction had a higher extraction yield of flavonoids with lower extraction time. Furthermore, flavonoids obtained by $\mathrm{SC}-\mathrm{CO}_{2}$ extraction showed better scavenging activities on hydroxyl, DPPH and ABTS radicals. Therefore, $\mathrm{SC}-\mathrm{CO}_{2}$ extraction can be considered as an alternative to CSE for the obtainment of flavonoids from pomelo peel.

\section{Acknowledgments}

We are grateful to Gang Wu and Nai-Xing Jiang from Universal Analytical \& Testing Ltd. for their guidance of supercritical technology.

\section{References}

1. Liu, J.; Lin, S.; Wang, Z.; Wang, C.; Wang, E.; Zhang, Y.; Liu, J. Supercritical fluid extraction of flavonoids from Maydis stigma and its nitrite-scavenging ability. Food Bioprod. Process. 2011, 89, 333-339.

2. Quan, C.; Li, S.; Tian, S.; Xu, H.; Lin, A.; Gu, L. Supercritical fluid extraction and clean-up of organochlorine pesticides in ginseng. J. Supercrit. Fluids 2004, 31, 149-157.

3. Cossuta, D.; Simándi, B.; Vági, E.; Hohmann, J.; Prechl, A.; Lemberkovics, É.; Kéry, Á.; Keve, T. Supercritical fluid extraction of Vitex agnus castus fruit. J. Supercrit. Fluids 2008, 47, 188-194.

4. Nik Norulaini, N.A.; Anuar, O.; Omar, A.K.M.; AlKarkhi, A.F.M.; Setianto, W.B.; Fatehah, M.O.; Sahena, F.; Zaidul, I.S.M. Optimization of $\mathrm{SC}-\mathrm{CO}_{2}$ extraction of zerumbone from Zingiber zerumbet (L) Smith. Food Chem. 2009, 114, 702-705. 
5. Lenucci, M.S.; Caccioppola, A.; Durante, M.; Serrone, L.; Leonardo, R.; Piro, G.; Dalessandro, G. Optimisation of biological and physical parameters for lycopene supercritical $\mathrm{CO}_{2}$ extraction from ordinary and high-pigment tomato cultivars. J. Sci. Food Agric. 2010, 90, 1709-1718.

6. Laitinen, A.; Kaunisto, J. Supercritical fluid extraction of 1-butanol from aqueous solutions. J. Supercrit. Fluids 1999, 15, 245-252.

7. Liza, M.S.; Abdul Rahman, R.; Mandana, B.; Jinap, S.; Rahmat, A.; Zaidul, I.S.M.; Hamid, A. Supercritical carbon dioxide extraction of bioactive flavonoid from Strobilanthes crispus (Pecah Kaca). Food Bioprod. Process. 2010, 88, 319-326.

8. Wang, Y.-C.; Chuang, Y.-C.; Hsu, H.-W. The flavonoid, carotenoid and pectin content in peels of citrus cultivated in Taiwan. Food Chem. 2008, 106, 277-284.

9. Bocco, A.; Cuvelier, M.-E.; Richard, H.; Berset, C. Antioxidant activity and phenolic composition of citrus peel and seed extracts. J. Agric. Food Chem. 1998, 46, 2123-2129.

10. Londoño-Londoño, J.; de Lima, V.R.; Lara, O.; Gil, A.; Pasa, T.B.C.; Arango, G.J.; Pineda, J.R.R. Clean recovery of antioxidant flavonoids from citrus peel: Optimizing an aqueous ultrasound-assisted extraction method. Food Chem. 2010, 119, 81-87.

11. Giannuzzo, A.N.; Boggetti, H.J.; Nazareno, M.A.; Mishima, H.T. Supercritical fluid extraction of naringin from the peel of Citrus paradisi. Phytochem. Anal. 2003, 14, 221-223.

12. Yi, Z.; Yu, Y.; Liang, Y.; Zeng, B. In vitro antioxidant and antimicrobial activities of the extract of Pericarpium Citri Reticulatae of a new Citrus cultivar and its main flavonoids. LWT-Food Sci. Technol. 2008, 41, 597-603.

13. Danh, L.T.; Mammucari, R.; Truong, P.; Foster, N. Response surface method applied to supercritical carbon dioxide extraction of Vetiveria zizanioides essential oil. Chem. Eng. J. 2009, $155,617-626$.

14. Wang, L.; Yang, B.; Du, X.; Yi, C. Optimisation of supercritical fluid extraction of flavonoids from Pueraria lobata. Food Chem. 2008, 108, 737-741.

15. Mannan, S.; Fakhru'l-Razi, A.; Alam, M.Z. Optimization of process parameters for the bioconversion of activated sludge by Penicillium corylophilum, using response surface methodology. J. Environ. Sci. 2007, 19, 23-28.

16. Vohra, A.; Satyanarayana, T. Statistical optimization of the medium components by response surface methodology to enhance phytase production by Pichia anomala. Process Biochem. 2002, 37, 999-1004.

17. Zhang, G.; He, L.; Hu, M. Optimized ultrasonic-assisted extraction of flavonoids from Prunella vulgaris L. and evaluation of antioxidant activities in vitro. Innovat. Food Sci. Emerg. Technol. 2011, 12, 18-25.

18. Kassama, L.S.; Shi, J.; Mittal, G.S. Optimization of supercritical fluid extraction of lycopene from tomato skin with central composite rotatable design model. Sep. Purif. Technol. 2008, 60, 278-284.

19. Shan, B.; Xie, J.-H.; Zhu, J.-H.; Peng, Y. Ethanol modified supercritical carbon dioxide extraction of flavonoids from Momordica charantia L. and its antioxidant activity. Food Bioprod. Process. 2012, 90, 579-587.

20. Liu, S.; Yang, F.; Zhang, C.; Ji, H.; Hong, P.; Deng, C. Optimization of process parameters for supercritical carbon dioxide extraction of Passiflora seed oil by response surface methodology. J. Supercrit. Fluids 2009, 48, 9-14. 
21. Montgomery, D.C. Design and Analysis of Experiments: Response Surface Method and Designs; John Wiley and Sons, Inc.: New Brunswick, NJ, USA, 2005.

22. Naik, G.H.; Priyadarsini, K.I.; Satav, J.G.; Banavalikar, M.M.; Sohoni, D.P.; Biyani, M.K.; Mohan, H. Comparative antioxidant activity of individual herbal components used in Ayurvedic medicine. Phytochemistry 2003, 63, 97-104.

23. Luo, A.; He, X.; Zhou, S.; Fan, Y.; Luo, A.; Chun, Z. Purification, composition analysis and antioxidant activity of the polysaccharides from Dendrobium nobile Lindl. Carbohyd. Polym. 2010 , 79, 1014-1019.

24. Ke, C.; Qiao, D.; Gan, D.; Sun, Y.; Ye, H.; Zeng, X. Antioxidant acitivity in vitro and in vivo of the capsule polysaccharides from Streptococcus equi subsp. zooepidemicus. Carbohyd. Polym. 2009, 75, 677-682.

25. Zarena, A.S.; Udaya Sankar, K. Supercritical carbon dioxide extraction of xanthones with antioxidant activity from Garcinia mangostana: Characterization by HPLC/LC-ESI-MS. J. Supercrit. Fluids 2009, 49, 330-337.

26. Kao, T.-H.; Chen, B.-H. Functional components in soybean cake and their effects on antioxidant activity. J. Agric. Food Chem. 2006, 54, 7544-7555.

27. Braca, A.; de Tommasi, N.; di Bari, L.; Pizza, C.; Politi, M.; Morelli, I. Antioxidant Principles from Bauhinia tarapotensis. J. Nat. Prod. 2001, 64, 892-895.

28. Fellegrini, N.; Ke, R.; Yang, M.; Rice-Evans, C. Screening of dietary carotenoids and carotenoid-rich fruit extracts for antioxidant activities applying 2,2'-azinobis(3ethylenebenzothiazoline-6-sulfonic acid radical cation decolorization assay. Methods Enzymol. 1999, 299, 379-389.

29. Smirnoff, N.; Cumbes, Q.J. Hydroxyl radical scavenging activity of compatible solutes. Phytochemistry 1989, 28, 1057-1060.

(C) 2012 by the authors; licensee MDPI, Basel, Switzerland. This article is an open access article distributed under the terms and conditions of the Creative Commons Attribution license (http://creativecommons.org/licenses/by/3.0/). 